\title{
Dietary fiber intake and mortality among survivors of myocardial infarction: prospective cohort study
}

\author{
(c) $(1)(9)$ OPEN ACCESS
}

\author{
Shanshan Li $\square$ doctoral candidate ${ }^{1}$, Alan Flint research scientist ${ }^{2}$, Jennifer K Pai assistant professor \\ of medicine ${ }^{3}$, John P Forman assistant professor of medicine ${ }^{4}$, Frank B Hu professor ${ }^{12}$, Walter C \\ Willett professor ${ }^{12}$, Kathryn M Rexrode associate professor of medicine ${ }^{5}$, Kenneth $\mathrm{J}$ Mukamal \\ associate professor of medicine ${ }^{6}$, Eric B Rimm associate professor ${ }^{12}$
}

${ }^{1}$ Department of Epidemiology, Harvard School of Public Health, 655 Huntington Avenue, Boston, MA 02115, USA; 'Department of Nutrition, Department of Epidemiology, Boston, MA, USA; ${ }^{3}$ Channing Division of Network Medicine, Brigham and Women's Hospital, Boston, MA, USA; ${ }^{4}$ Renal Division, Brigham and Women's Hospital, Boston, MA, USA; ${ }^{5}$ Department of Preventive Medicine, Brigham and Women's Hospital, Boston, MA, USA; ${ }^{6}$ General Medicine, Beth Israel Deaconess Medical Center, Brookline, MA, USA

\begin{abstract}
Objective To evaluate the associations of dietary fiber after myocardial infarction (MI) and changes in dietary fiber intake from before to after MI with all cause and cardiovascular mortality.

Design Prospective cohort study.

Setting Two large prospective cohort studies of US women and men with repeated dietary measurements: the Nurses' Health Study and the Health Professionals Follow-Up Study.
\end{abstract}

Participants 2258 women and 1840 men who were free of cardiovascular disease, stroke, or cancer at enrollment, survived a first MI during follow-up, were free of stroke at the time of initial onset of MI, and provided food frequency questionnaires pre-Ml and at least one post-MI.

Main outcome measures Associations of dietary fiber post-MI and changes from before to after MI with all cause and cardiovascular mortality using Cox proportional hazards models, adjusting for drug use, medical history, and lifestyle factors.

Results Higher post-MI fiber intake was significantly associated with lower all cause mortality (comparing extreme fifths, pooled hazard ratio $0.75,95 \%$ confidence interval 0.58 to 0.97 ). Greater intake of cereal fiber was more strongly associated with all cause mortality (pooled hazard ratio $0.73,0.58$ to 0.91 ) than were other sources of dietary fiber. Increased fiber intake from before to after MI was significantly associated with lower all cause mortality (pooled hazard ratio $0.69,0.55$ to 0.87 ).

Conclusions In this prospective study of patients who survived MI, a greater intake of dietary fiber after MI, especially cereal fiber, was inversely associated with all cause mortality. In addition, increasing consumption of fiber from before to after MI was significantly associated with lower all cause and cardiovascular mortality.

\section{Introduction}

Diet plays an important role in the etiology of atherosclerosis and coronary heart disease, ${ }^{1}$ yet secondary prevention guidelines generally emphasize pharmaceutical management owing to the lack of evidence to guide diet and lifestyle recommendations. ${ }^{2-8}$ The need for better lifestyle guidelines for survivors of myocardial infarction (MI) is profound especially because a substantial drop in the case fatality rate has increased the number of survivors in the United States. ${ }^{9}$ Compared with the general population, this growing patient population is at higher risk for mortality and may be more motivated to change their lifestyle habits. Evidence as to whether and to what extent dietary changes from before to after MI improve prognosis is, however, insufficient.

Greater intake of dietary fiber improves glycemic response and insulin sensitivity, increases the production of short chain fatty acids, and increases satiety to help control overall energy intake. ${ }^{10}{ }^{11}$ Dietary fiber is inversely associated with risk of dyslipidemia, hypertension, obesity, diabetes, peripheral vascular disease, coronary heart disease, and stroke..$^{12-17}$

The Diet and Reinfarction Trial (DART), the only clinical trial of dietary fiber intake among 2033 male survivors of MI, did not show a lower rate of coronary and total deaths with increased fiber intake during two years of follow-up after MI. ${ }^{18}{ }^{19}$ However, the study was limited by the short duration of follow-up, poor compliance to the dietary intervention, and generalizability of 
the patient population. The DART trial was also conducted almost 30 years ago. With more sensitive diagnostic criteria for onset of MI and greater advances in clinical management, the population of survivors of MI now differs from those at that time. Thus, it is unknown what the long term impact of diet and lifestyle change may have in a contemporary post-MI population.

The Nurses' Health Study (NHS) and the Health Professional Follow-up Study (HPFS) are two large prospective cohort studies of US women and men with repeated dietary measurements both before and after MI. Using data from these two cohorts, we evaluated the association of dietary fiber intake during the post-MI period, pre-MI period, and changes from before to after MI on survival.

\section{Methods}

\section{Study population}

The Nurses' Health Study is a prospective cohort of 121700 US registered female nurses, aged 30-55 years in 1976. The Health Professional Follow-up Study is a prospective cohort of 51529 US male health professionals, aged 40-75 years in 1986. In both studies the participants received detailed biennial questionnaires on lifestyle and medical history.

We assessed diet and lifestyle characteristics among 2639 women and 2081 men who were free of cardiovascular disease, stroke, or cancer at enrollment (1976 for women and 1986 for men), survived a first MI during the follow-up through 2008, and were free of stroke at the time of initial onset of MI. The pre-MI period was defined as the time between the study enrollment and the return of the last food frequency questionnaire before the onset of MI. The post-MI period was the time from the date of the first food frequency questionnaire (FFQ) returned after the initial onset of MI until death or the end of the study period, whichever occurred first.

From the incident non-fatal MI events, we restricted our analysis to participants who provided both pre-MI exposure information and at least one post-MI food frequency questionnaire (2258 for women and 1840 for men). We excluded participants (381 for women and 241 for men; see supplementary table) who died before the return of the first post-MI food frequency questionnaire or whose post-MI dietary assessment was incomplete.

\section{Exposure assessment}

Dietary habits were assessed with a validated food frequency questionnaire every four years from 1976-2006 for the Nurses' Health Study and from 1986-2006 for the Health Professionals Follow-up Study. The food frequency questionnaire assesses average food intake over the previous year. Consumption of each food is based on a commonly used unit or portion size, with nine possible response categories of intake frequency, ranging from "never" to "6 or more times per day." Each category is assigned a weight representing the midpoint of that category. Estimates from the food frequency questionnaire adequately reflect long term average dietary fiber intake based on several weeks of formal diet records ( $\mathrm{r}=0.68$ for dietary fiber, $r=0.79$ for cold breakfast cereal, the major source of fiber in these two populations). ${ }^{20-22}$

We obtained the dietary fiber content of foods from the Harvard food composition database, which is a compilation of data from the United States Department of Agriculture, the published literature, food manufacturers, and outside consultation with experts. We calculated energy adjusted values for all nutrients including fiber to estimate the composition of dietary fiber in the diet, independent of the total quantity of food reported. ${ }^{23}$

\section{Identification of incident MI}

After participants self reported an incident MI, we sent them a computer generated personalized letter requesting permission to access their medical records. For non-respondents $(<5 \%$ of all men and women reporting a non-fatal MI), a research nurse telephoned them to obtain further details on their diagnosis and to seek permission for their medical records to be reviewed. Study physicians reviewed the records blinded to the participants' exposure status. Myocardial infarction was confirmed according to symptoms plus either diagnostic electrocardiographic changes or increased levels of cardiac enzymes, including cardiac specific troponin. ${ }^{24}$

\section{Outcome assessment}

Our primary outcomes were all cause and cardiovascular mortality. We identified deaths occurring after the first non-fatal MI during follow-up from vital records, the national death index, and reports by the participant's next of kin, or the postal system. ${ }^{25}$ Our outcome of cardiovascular mortality consisted of fatal MI, fatal stroke, and coronary heart disease, which were confirmed through a review of medical records or autopsy reports with the permission of the next of kin.

\section{Covariate assessment}

Covariates were chosen a priori based on previous studies. We considered dietary covariates, medication use, medical history, and lifestyles factors. Covariates were assessed from the questionnaire immediately preceding the initial onset of MI and updated with each subsequent questionnaire cycle. In the Health Professionals Follow-up Study, we also considered detailed clinical characteristics obtained through medical chart review, including ST segment elevation MI (yes or no), site of initial MI (anterior, inferior, and other), revascularization at the time of MI (primary angioplasty or thrombolytic therapy, versus none), left ventricular ejection fraction $(\geq 40 \%,<40 \%$, or missing), initial creatinine levels (continuous), and heart failure during hospital stay (yes or no).

We included known predictors of MI survival and potential confounders that changed the $\beta$ coefficient by at least $10 \%$. In the final model, covariates not included due to limited evidence of confounding were family history of MI, hypercholesterolemia, height, protein intake, polyunsaturated fat intake, multivitamin use, glycemic index, site of MI, ST elevation, and initial creatinine level.

\section{Statistical analysis}

We defined change of dietary fiber from before to after MI as the absolute difference between energy adjusted fiber intake from the first post-MI food frequency questionnaire and the most recent pre-MI food frequency questionnaire. We considered both simple updated and cumulative average of fiber intake as described elsewhere ${ }^{26}$ and presented simple updated analyses because of similar results. For missing data in the exposure and covariates, we carried forward the value reported in the previous post-MI questionnaire cycle.

We used a Cox proportional hazards model with time since return of the first post-MI food frequency questionnaire as the underlying time scale. Person months were calculated from the date of the first food frequency questionnaire returned after initial MI until death or the end of study period, whichever came 
first. We also evaluated the association between pre-MI fiber intake with post-MI survival starting at the date of initial onset of MI. The proportional hazards assumption was tested by modeling multiplicative interaction terms between time and the primary exposure variable. For analyses of trends, we fit medians of each fifth as a continuous variable.

To evaluate potential survivor bias related to the requirement that each participant had to have at least one post-MI dietary assessment, we estimated the probability of not being missing, and then reweighted the study population by the inverse of this probability. ${ }^{27}$

For the association between post-MI dietary fiber and mortality, we tested for possible effect modification by body mass index ( $<25$ or $\geq 25 \mathrm{~kg} / \mathrm{m}^{2}$ ), physical activity level (highest two fifths versus lowest three fifths), and glycemic load (thirds) using the likelihood ratio test. Because previous studies suggest a potential interaction between fiber intake and lipid lowering medications, ${ }^{28}$ we also explored interactions with aspirin use (yes, no) and use of lipid lowering medications (yes, no). We performed analyses in men and women separately and evaluated heterogeneity of results using the Cochrane Q statistics. ${ }^{29}$ To pool results across the sexes, we used fixed effect models in the absence of significant heterogeneity, and random effect models otherwise. $^{30} 31$

Dietary habits pre-MI (habitual diet) might affect post-MI survival. We tested the hypothesis of a "carry-over effect" of the pre-MI diet on post-MI mortality, adjusting for covariates from the period before MI. To examine the association between changes in dietary fiber in the period from before to after MI and survival, we also adjusted for changes in covariates during that period. For models with missing covariates, we tested three different methods (missing indicator, imputed with median, and assuming no change from before to after MI periods) with similar results, and therefore we present only the results using the missing indicator method. We also modeled fiber intake by nine subgroups of pre-MI (thirds) and post-MI fiber intake (thirds) and used the likelihood ratio test to examine the interaction between pre-MI and post-MI intake.

To ensure that the food frequency questionnaire only reflected post-MI intake, we conducted sensitivity analyses that only included participants whose first post-MI food frequency questionnaire was returned at least 12 months after initial MI. We additionally adjusted for $\beta$ blocker use during the post-MI period. Because lack of physical activity may indicate frailty and severity of diseases, we also performed further sensitivity analyses adjusting for physical activity with a two year lag or excluding participants in the lowest fifth of physical activity. We performed all statistical analyses using the Statistical Analysis System 9.2 (SAS Institute).

\section{Results}

During 32 years of follow-up in women and 22 years in men, we documented 2258 women and 1840 men with incident MI and dietary assessments both before and after MI. Table $1 \Downarrow$ summarizes the age standardized baseline characteristics of the study population by fifths of energy adjusted fiber intake, with baseline defined as the first questionnaire cycle post-MI.

The median follow-up post-MI was 8.7 years for women and 9.0 years for men. During the follow-up, we confirmed 682 total and 336 cardiovascular deaths for women, and 451 total and 222 cardiovascular deaths for men.

Higher post-MI fiber intake was significantly associated with lower all cause mortality in age adjusted models for both men and women (table $2 \Downarrow$ ). Further adjustment for lifestyle characteristics and dietary factors attenuated these associations, but the pooled hazard ratio remained significantly inverse (table 2). When we modeled fiber as a continuous variable, the pooled hazard ratio was 0.85 (95\% confidence interval 0.74 to 0.97 ) for total mortality for a $10 \mathrm{~g} /$ day increment in intake. Our results were similar after using inverse probability weighting to account for potential selection bias (comparing extreme fifths, pooled hazard ratio $0.89,0.74$ to $1.07, \mathrm{P}$ for heterogeneity $=0.13$ ). Further adjustment for pre-MI diet did not substantially alter associations for post-MI diet.

To evaluate whether the association differed by fiber type, we jointly examined cereal fiber, fruit fiber, and vegetable fiber. Only intake of cereal fiber was strongly inversely associated with lower all cause and cardiovascular mortality: pooled hazard ratio 0.73 ( 0.58 to 0.91 ) for all cause mortality, 0.72 ( 0.52 to 0.99 ) for cardiovascular mortality (figure $\Downarrow$ ).

No significant effect modification by body mass index, physical activity level, glycemic load, aspirin or lipid lowering medication use was observed. Results were also similar after excluding participants with food frequency questionnaires returned within 12 months of initial onset of MI, excluding participants in the lowest fifth of physical activity, using a two year lag for physical activity or additionally adjusting for $\beta$ blocker use (data not shown).

Pre-MI dietary fiber was not associated with post-MI mortality (highest fifth versus lowest fifth, pooled hazard ratio 1.17, 0.92 to 1.48 for all cause mortality and $1.10,0.77$ to 1.55 for cardiovascular mortality).

We also examined associations for change in fiber intake from before to after MI. Participants on average increased their fiber intake from the before to after MI period (table $3 \Downarrow$ ). Spearman correlations for fiber intake between pre-MI and the first post-MI were 0.48 for women and 0.53 for men. A greater increase in fiber intake was significantly associated with lower all cause and cardiovascular mortality in both sexes. Compared with participants who were in the lowest third of fiber intake in both pre-MI and post-MI periods, participants in the highest third in both periods had the lowest all cause mortality: hazard ratio 0.73 (95\% confidence interval 0.54 to 0.99 ), $\mathrm{P}$ for interaction $=0.01$ for women, and 0.81 ( 0.58 to 1.13$)$, $\mathrm{P}$ for interaction $=0.16$ for men.

\section{Discussion}

In this prospective study of dietary intake after myocardial infarction (MI), greater intake of dietary fiber, especially cereal fiber, was inversely associated with all cause mortality. Participants increased their average dietary fiber intake after MI, and the greater the increase, the lower was the risk of subsequent all cause and cardiovascular mortality. Overall, the benefits for increased fiber intake were strongest for fiber from cereal and grain sources.

Possible mechanisms for the beneficial effects of a high fiber diet on coronary heart disease risk and mortality include reductions in systemic inflammation, lower serum low density lipoprotein cholesterol level, reduced lipid peroxidation, improved insulin sensitivity, overall better glycemic control, and a beneficial gut microbiota environment. ${ }^{32-34}$ Many biomarkers for these pathways have been studied in the prediction of incident coronary heart disease, but few with the exception of hyperlipidemia or inflammation have been examined in patients post-MI..$^{35-40}$ It is likely that these mechanisms would be similar in the post-MI environment, but 
mechanisms to explain lower overall mortality have not been as thoroughly explored.

The benefits of fiber we observed were mainly from cereal and grain sources. In the general population, a $20-40 \%$ risk reduction in coronary heart disease has consistently been observed among those who consume fiber-rich whole grains regularly, ${ }^{13}$ yet less than $5 \%$ of Americans consume the minimum recommended fiber intake of $25 \mathrm{~g} /$ day for women and $38 \mathrm{~g} /$ day for men. ${ }^{41} \mathrm{In}$ our study, the association with all cause mortality was stronger than with cardiovascular mortality. This may occur because patients who have experienced MI are initially and increasingly targeted for intensive medical and therapeutic management to reduce their risk of recurrent cardiovascular events, and less so for the many other causes of death. Because dietary fiber has broad effects on other causes of death, our results may reflect the success of secondary prevention in the past two decades.

Our results differ from the original DART trial, which is the only existing study on dietary fiber in secondary prevention. The DART trial showed that a high cereal fiber diet post-MI did not reduce mortality among men only. ${ }^{18}{ }^{19}$ In that study, 2033 survivors of MI under age 70 (mean age 56.5 years) were randomly assigned to dietary interventions that consisted of counseling to consume either a low fat diet with a high polyunsaturated to saturated fat ratio, a high fatty fish diet, or a diet with a target of $18 \mathrm{~g} /$ day of cereal fiber and $30 \mathrm{~g} /$ day of total dietary fiber. ${ }^{19}$ After two years of follow-up, self reported compliance was good, but no objective measure of fiber intake was assessed. ${ }^{18}$ Based on the reported average intake from dietary questionnaires at six months, only $50 \%$ of the population achieved the target of $18 \mathrm{~g}$ /day of cereal fiber, ${ }^{18}{ }^{19}$ and even fewer reached the fiber target. Interestingly, when recontacted approximately 10 years later, the $50 \%$ of DART participants still alive reported noticeably reduced intake of cereal fiber $(6.2$ $\mathrm{g} /$ day in the intervention arm and $5.0 \mathrm{~g} / \mathrm{day}$ in the control arm), and there was no difference in mortality between the two groups. ${ }^{42}$ Thus it is likely that compliance was a major challenge in this trial. Finally, participants were excluded at baseline if they were already on a high cereal fiber diet or had the intention to change to such a diet, leaving a study population of participants less likely to comply. Thus, with short follow-up, modest compliance, and a highly selective population, it is difficult to generalize the null results from DART trial to our free-living population with almost a decade of follow-up, a broader age range, and no restraints on baseline diet at enrollment. The PREDIMED (Prevencion con Dieta Mediterranea) study provided convincing evidence for the beneficial effects of the Mediterranean diet, high in monounsaturated fats from nuts and extra virgin olive oil and rich in fruits, vegetables, legumes, and non-refined grains, on cardiovascular risk reduction. ${ }^{43}$ Although it is not possible to identify the specific aspects of the PREDIMED diets that reduced cardiovascular disease, increasing fiber intake may have contributed.

\section{Limitations of this study}

Our study has several limitations. Firstly, our food frequency questionnaire is a reliable measure for assessing dietary intake in the previous year, ${ }^{20-46}$ but its validity is not known for measuring intake within the same person before and after MI. The time interval for the food frequency questionnaires covering the period between before and after MI could be up to eight years. However, our results were similar after sensitivity analyses excluding patients with missing information on the first post-MI food frequency questionnaire.
Our results may be confounded by beneficial factors related to fiber intake; foods that are high in fiber, such as whole grains, fruits, and vegetables, also contain vitamins, minerals, antioxidants, and phytochemicals, which may also be beneficial for health. Medication use and severity of the initial MI are also potential unmeasured confounders. Patients who consumed a high fiber diet or changed to a high fiber diet after MI may also have changed to many other healthy lifestyle factors post-MI, which lowered subsequent mortality rates. We adjusted for major confounders in our analyses, such as medication use, other dietary factors, and physical activity using data from questionnaires administered at the same time as the post-MI food frequency questionnaire. Despite the adjustment in our pooled analysis, a higher fiber diet post-MI was associated with long term reduced mortality. We also had a relatively homogeneous population of health professionals, thus further reducing potential residual confounding by unmeasured factors associated with socioeconomic status. For changes in fiber from before MI to after MI analyses, we cannot fully adjust for all known or unknown healthy lifestyle changes, and results may still be subject to modest residual and unmeasured confounding. We conducted sensitivity analyses using medication non-compliance as a potential unknown residual confounder (see web extra appendix). We found that the relative risk was only meaningfully attenuated in extreme conditions where the association of medication non-compliance and fiber intake is strong (40-45\% difference in adherence prevalence) and where the association with non-compliance and mortality is strong (relative risk 2-3). We believe this is unlikely to occur because these strong associations would need to be independent of known covariates already in our model. Unfortunately, few large studies of clinical populations include the detailed dietary information necessary for confirmation of our findings.

This study was limited to participants who had at least one before MI and one after MI food frequency questionnaire. Participants who died before the return of the first post-MI questionnaire or did not return a post-MI one were not included in the study. This could introduce a selection bias by excluding patients who may be least sensitive to the benefits of dietary modification. We used the inverse probability weighting method to assess the impact of this bias and found that the results were essentially unchanged.

Even with two of the largest long term prospective cohorts of post-MI, we still had limited power to examine cause specific mortality. We also were not able to examine optimal timing for change in diet or potential interactions between dietary fiber and post-MI medications. Future research on lifestyle changes post-MI should focus on a combination of lifestyle changes and how they may further reduce mortality rates beyond what is achievable by medical management alone.

Our analyses should be viewed in the context of recent concerns about unrealistic findings in nutritional epidemiology. ${ }^{47}$ Randomized trials of specific dietary factors could be problematic and are subject to serious difficulties and bias due to non-compliance and attrition and can rarely test all hypothesis based research questions. As a result, our findings, in conjunction with feeding studies, other observational data, and the success of nutritional interventions in post-MI care suggested by the Lyon Heart Study, provide robust evidence of the benefits of fiber for the large population of survivors of MI.

\section{Strengths of this study}

The strengths of our study include the large sample size and long duration of follow-up from two prospective cohort studies, 
with follow-up rates in excess of $90 \%$ in each two year cycle. Our study measured dietary intake repeatedly in both before MI and after MI periods to reduce measurement error, and used validated lifestyle questionnaires to assess other important risk factors for survival.

\section{Conclusion}

Greater intake of dietary fiber after MI, especially cereal fiber, was inversely associated with all cause and cardiovascular mortality. In addition, participants who increased their dietary fiber intake after MI had lower long term rates of all cause and cardiovascular mortality.

We thank Lydia Liu, Donna Spiegelman, and Ellen Hertzmark for their help with programming; the staff and participants in the Nurses' Health Study and the Health Professionals Follow-up Study, Channing Division of Network Medicine, Department of Medicine, Brigham and Women's Hospital and Harvard Medical School.

Contributors: SL had full access to all of the data in the study and takes responsibility for the integrity of the data and the accuracy of the data analysis. EBR and KJM conceived and designed the study and analysed and interpreted the data. EBR, WCW, FBH, and KJM acquired the data. SL and EBR drafted the manuscript. SL, EBR, WCW, FBH, KJM, AF, MJKP, and JPF critically revised the manuscript for important intellectual content. SL carried out the statistical analysis. EBR and WCW obtained funding. EBR, WCW, FBH, and KJM, and AF were responsible for administrative, technical, or material support and study supervision. EBR is guarantor.

Funding: This study was supported by National Institute of Health grants AA11181, HL35464, HL34594, HL60712, CA55075, CA87969, and CA055075. The funders play no role in the study design, data collection, analysis and interpretation, the writing of the manuscript, and the decision to submit the article for publication.

Competing interests: All authors have completed the ICMJE uniform disclosure form at www.icmje.org/coi_disclosure.pdf (available on request from the corresponding author) and declare: no support from any organisation for the submitted work; AF receives research funding for a separate unrelated project from the General Mills Bell Institute of Nutrition; no financial relationships with any organisation that might have an interest in the submitted work in the previous three years; no other relationships or activities that could appear to have influenced the submitted work.

Ethical approval: This study was approved by institutional review board at Harvard School of Public Health (ID of the approval: 2008P000327). Study participants gave informed consent before taking part.

Data sharing: No additional data available.

Transparency: The lead author (the manuscript's guarantor) affirms that the manuscript is an honest, accurate, and transparent account of the study being reported; that no important aspects of the study have been omitted; and that any discrepancies from the study as planned (and, if relevant, registered) have been explained.

\section{Hu FB, Willett WC. Optimal diets for prevention of coronary heart disease. JAMA} 2002;288:2569-78.

2 Wright RS, Anderson JL, Adams CD, Bridges CR, Casey DE Jr, Ettinger SM, et al. American College of Cardiology Foundation/American Heart Association Task Force on Practice Guidelines. 2011 ACCF/AHA focused update incorporated into the ACC/AHA 2007 guidelines for the management of patients with unstable angina/non-ST-elevation myocardial infarction: a report of the American College of Cardiology Foundation/American Heart Association Task Force on Practice Guidelines developed in collaboration with the American Academy of Family Physicians, Society for Cardiovascular Angiography and Interventions, and the Society of Thoracic Surgeons. J Am Coll Cardiol . 2011;57:e215-367.

3 Perk J, De Backer G, Gohlke H, Graham I, Reiner Z, Verschuren M, et al. European Association for Cardiovascular Prevention \& Rehabilitation (EACPR); ESC Committee for Practice Guidelines (CPG). European guidelines on cardiovascular disease prevention in clinical practice (version 2012). The Fifth Joint Task Force of the European Society of Cardiology and Other Societies on Cardiovascular Disease Prevention in Clinical Practice (constituted by representatives of nine societies and by invited experts). Eur Heart $J$ 2012;33:1635-701.
4 Alpert JS, Thygesen K, Antman E, Bassand JP. Myocardial infarction redefined-a consensus document of The Joint European Society of Cardiology/American College of Cardiology Committee for the redefinition of myocardial infarction. J Am Coll Cardiol 2000;36:959-69

5 American College of Emergency Physicians; Society for Cardiovascular Angiography and Interventions. O'Gara PT, Kushner FG, Ascheim DD, Casey DE Jr, Chung MK, de Lemos JA, et al. 2013 ACCF/AHA guideline for the management of ST-elevation myocardial infarction: a report of the American College of Cardiology Foundation/American Heart Association Task Force on Practice Guidelines. J Am Coll Cardiol 2013;61:e78-140.

6 Kushner FG, Hand M, Smith SC Jr, King SB 3rd, Anderson JL, Antman EM, et al. American College of Cardiology Foundation/American Heart Association Task Force on Practice Guidelines. 2009 Focused updates: ACC/AHA guidelines for the management of patients with ST-elevation myocardial infarction (updating the 2004 guideline and 2007 focused update) and ACC/AHA/SCAl guidelines on percutaneous coronary intervention (updating the 2005 guideline and 2007 focused update): a report of the American College of Cardiology Foundation/American Heart Association Task Force on Practice Guidelines. Circulation 2009;120:2271-306.

7 Mead A, Atkinson G, Albin D, Alphey D, Baic S, Boyd O, et al. UK Heart Health Group; Thoracic Dietitians Interest Group (specialist group of the British Dietetic Association). Dietetic guidelines on food and nutrition in the secondary prevention of cardiovascular disease - evidence from systematic reviews of randomized controlled trials (second update, January 2006). J Hum Nutr Diet 2006;19:401-19.

8 Skinner JS, Cooper A, Feder GS. Secondary prevention for patients after a myocardial infarction: summary of NICE guidance. BMJ 2007;334:1112-3.

9 Wellenius GA, Mittleman MA. Disparities in myocardial infarction case fatality rates among the elderly: the 20-year Medicare experience. Am Heart J 2008;156:483-90

10 Ha MA, Jarvis MC, Mann JI. A definition for dietary fibre. Eur J Clin Nutr 2000;54:861-4

11 Anderson JW, Baird P, Davis RH Jr, Ferreri S, Knudtson M, Koraym A, et al. Health benefits of dietary fiber. Nutr Rev 2009;67:188-205.

12 Flight I, Clifton P. Cereal grains and legumes in the prevention of coronary heart disease and stroke: a review of the literature. Eur J Clin Nutr 2006;60:1145-59.

13 Satija A, Hu FB. Cardiovascular benefits of dietary fiber. Curr Atheroscler Rep 2012;14:505-14.

14 Liu S, Buring JE, Sesso HD, Rimm EB, Willett WC, Manson JE. A prospective study of dietary fiber intake and risk of cardiovascular disease among women. J Am Coll Cardiol 2002;39:49-56.

15 Rimm EB, Ascherio A, Giovannucci E, Spiegelman D, Stampfer MJ, Willett WC. Vegetable, fruit, and cereal fiber intake and risk of coronary heart disease among men. JAMA 1996;275:447-51.

16 Wolk A, Manson JE, Stampfer MJ, Colditz GA, Hu FB, Speizer FE, et al. Long-term intake of dietary fiber and decreased risk of coronary heart disease among women. JAMA 1999;281:1998-2004.

17 Mente A, de Koning L, Shannon HS, Anand SS. A systematic review of the evidence supporting a causal link between dietary factors and coronary heart disease. Arch Intern Med 2009;169:659-69.

18 Burr ML, Fehily AM, Gilbert JF, Rogers S, Holliday RM, Sweetnam PM, et al. Effects of changes in fat, fish, and fibre intakes on death and myocardial reinfarction: diet and reinfarction trial (DART). Lancet 1989;2:757-61.

19 Burr ML. Secondary prevention of CHD in UK men: the Diet and Reinfarction Trial and its sequel. Proc Nutr Soc 2007;66:9-15.

20 Rimm EB, Giovannucci EL, Stampfer MJ, Colditz GA, Litin LB, Willett WC. Reproducibility and validity of an expanded self-administered semiquantitative food frequency questionnaire among male health professionals. Am J Epidemiol 1992;135:1114-26.

21 Willett WC, Sampson L, Stampfer MJ, Rosner B, Bain C, Witschi J, et al. Reproducibility and validity of a semiquantitative food frequency questionnaire. Am J Epidemiol 1985;122:51-65.

22 Willett WC, Sampson L, Browne ML, Stampfer MJ, Rosner B, Hennekens CH, et al. The use of a self-administered questionnaire to assess diet four years in the past. $A m \mathrm{~J}$ Epidemiol 1988;127:188-99.

23 Willett WC, Stampfer MJ. Total energy intake: implications for epidemiologic analyses. Am J Epidemiol 1986;124:17-27.

24 Luepker RV, Apple FS, Christenson RH, Crow RS, Fortmann SP, Goff D, et al. AHA Council on Epidemiology and Prevention; AHA Statistics Committee; World Heart Federation Council on Epidemiology and Prevention; European Society of Cardiology Working Group on Epidemiology and Prevention; Centers for Disease Control and Prevention; National Heart, Lung, and Blood Institute. Case definitions for acute coronary heart disease in epidemiology and clinical research studies: a statement from the AHA Council on Epidemiology and Prevention; AHA Statistics Committee; World Heart Federation Council on Epidemiology and Prevention; the European Society of Cardiology Working Group on Epidemiology and Prevention; Centers for Disease Control and Prevention; and the National Heart, Lung, and Blood Institute. Circulation 2003;108:2543-9.

25 Rich-Edwards JW, Corsano KA, Stampfer MJ. Test of the national death index and equifax nationwide death search. Am J Epidemiol 1994;140:1016-9.

26 Hu FB, Stampfer MJ, Rimm E, Ascherio A, Rosner BA, Spiegelman D, et al. Dietary fat and coronary heart disease: a comparison of approaches for adjusting for total energy intake and modeling repeated dietary measurements. Am J Epidemiol 1999:149:531-40.

27 Cole SR, Hernán MA. Constructing inverse probability weights for marginal structural models. Am J Epidemiol 2008;168:656-64.

28 Schmidt LE, Dalhoff K. Food-drug interactions. Drugs 2002;62:1481-502.

29 Higgins JP, Thompson SG. Quantifying heterogeneity in a meta-analysis. Stat Med 2002;21:1539-58

30 Higgins JP, Thompson SG, Deeks JJ, Altman DG. Measuring inconsistency in meta-analyses. BMJ 2003;327:557-60

31 DerSimonian R, Laird N. Meta-analysis in clinical trials. Control Clin Trials 1986;7:177-88.

32 Park Y, Subar AF, Hollenbeck A, Schatzkin A. Dietary fiber intake and mortality in the NIH-AARP Diet and Health Study. Arch Intern Med 2011;171:1061-8.

33 Dandona P, Ghanim H, Chaudhuri A, Dhindsa S, Kim SS. Macronutrient intake induces oxidative and inflammatory stress: potential relevance to atherosclerosis and insulin resistance. Exp Mol Med 2010;42:245-53.

34 Wong JM, Esfahani A, Singh N, Villa CR, Mirrahimi A, Jenkins DJ, et al. Gut microbiota, diet, and heart disease. J AOAC Int 2012;95:24-30.

35 Hall AS, Jackson BM, Farrin AJ, Efthymiou M, Barth JH, Copeland J, et al. SPACE ROCKET Trial Group. A randomized, controlled trial of simvastatin versus rosuvastatin in patients with acute myocardial infarction: the Secondary Prevention of Acute Coronary 


\section{What is already known on this topic}

Dietary fiber is associated with lower risk of coronary heart disease in healthy populations

It is unclear whether higher consumption of dietary fiber after myocardial infarction (MI) is associated with lower mortality

\section{What this study adds}

In this prospective study of survivors after MI, a greater intake of dietary fiber, especially cereal fiber, after MI was inversely associated with all cause mortality

In addition, increasing consumption of fiber from the period before to after MI was significantly associated with a $31 \%$ lower all cause mortality and $35 \%$ lower cardiovascular mortality

Events-Reduction of Cholesterol to Key European Targets Trial. Eur J Cardiovasc Prev Rehabil 2009;16:712-21.

36 Johnson C, Waters DD, DeMicco DA, Breazna A, Bittner V, Greten H, et al. Comparison of effectiveness of atorvastatin $10 \mathrm{mg}$ versus $80 \mathrm{mg}$ in reducing major cardiovascular events and repeat revascularization in patients with previous percutaneous coronary intervention (post hoc analysis of the Treating to New Targets [TNT] Study). Am J Cardiol 2008;102:1312-7.

37 Bonnet J, McPherson R, Tedgui A, Simoneau D, Nozza A, Martineau P, et al. CAP Investigators. Comparative effects of $10-\mathrm{mg}$ versus $80-\mathrm{mg}$ atorvastatin on high-sensitivity C-reactive protein in patients with stable coronary artery disease: results of the CAP (Comparative Atorvastatin Pleiotropic effects) study. Clin Ther 2008;30:2298-313.

38 Nissen SE, Nicholls SJ, Sipahi I, Libby P, Raichlen JS, Ballantyne CM, et al. ASTEROID Investigators. Effect of very high-intensity statin therapy on regression of coronary atherosclerosis: the ASTEROID trial. JAMA 2006;295:1556-65.

39 LaRosa JC, Grundy SM, Waters DD, Shear C, Barter P, Fruchart JC, et al. Treating to New Targets (TNT) Investigators. Intensive lipid lowering with atorvastatin in patients with stable coronary disease. N Engl J Med 2005;352:1425-35.

40 Shepherd J, Barter P, Carmena R, Deedwania P, Fruchart JC, Haffner S, et al. Effect of lowering LDL cholesterol substantially below currently recommended levels in patients with coronary heart disease and diabetes: the Treating to New Targets (TNT) study. Diabetes Care 2006;29:1220-6.

41 United States Department of Agriculture. The dietary guidelines for Americans, 2010. 2014. www.cnpp.usda.gov/dietaryguidelines.htm.

42 Ness AR, Hughes J, Elwood PC, Whitley E, Smith GD, Burr ML. The long-term effect of dietary advice in men with coronary disease: follow-up of the Diet And Reinfarction Trial (DART). Eur J Clin Nutr . 2002;56:512-8.
43 Estruch R, Ros E, Salas-Salvadó J, Covas MI, Corella D, Arós F, et al. Primary prevention of cardiovascular disease with a Mediterranean diet. N Engl J Med 2013;368:1279-90.

44 Estruch R, Martínez-González MA, Corella D, Basora-Gallisá J, Ruiz-Gutiérrez V, Covas $\mathrm{MI}$, et al. PREDIMED Study Investigators. Effects of dietary fibre intake on risk factors for cardiovascular disease in subjects at high risk. $J$ Epidemiol Community Health 2009;63:582-8.

45 Feskanich D, Rimm EB, Giovannucci EL, Colditz GA, Stampfer MJ, Litin LB, et al. Reproducibility and validity of food intake measurements from a semiquantitative food frequency questionnaire. J Am Diet Assoc 1993;93:790-6.

46 Hu FB, Rimm E, Smith-Warner SA, Feskanich D, Stampfer MJ, Ascherio A, et al. Reproducibility and validity of dietary patterns assessed with a food-frequency questionnaire. Am J Clin Nutr 1999;69:243-9.

47 loannidis JP. Implausible results in human nutrition research. BMJ 2014;348:g2659.

Accepted: 31 March 2014

\section{Cite this as: BMJ 2014;348:g2659}

This is an Open Access article distributed in accordance with the Creative Commons Attribution Non Commercial (CC BY-NC 3.0) license, which permits others to distribute, remix, adapt, build upon this work non-commercially, and license their derivative works on different terms, provided the original work is properly cited and the use is non-commercial. See: http://creativecommons.org/licenses/by-nc/3.0/. 


\section{Tables}

Table 1| Age standardized baseline characteristics of 2258 women in the Nurses' Health Study and 1840 men in the Health Professional Follow-up Study by fifths of fiber intake after initial myocardial infarction (MI). Values are percentages unless stated otherwise

\begin{tabular}{|c|c|c|c|c|c|c|}
\hline \multirow[t]{2}{*}{ Characteristics } & \multicolumn{3}{|c|}{ Women } & \multicolumn{3}{|c|}{ Men } \\
\hline & Lowest fifth & Third fifth & Highest fifth & Lowest fifth & Third fifth & Highest fifth \\
\hline No of participants & 433 & 437 & 457 & 367 & 373 & 358 \\
\hline Mean (SD) post-MI fiber intake* & $12.4(2.0)$ & $19.2(0.8)$ & $28.7(4.4)$ & $16.0(2.4)$ & $24.4(1.0)$ & $37.0(5.8)$ \\
\hline Mean (SD) pre-Ml fiber intake† & $14.0(4.6)$ & $17.5(4.6)$ & $22.2(6.6)$ & $17.3(4.9)$ & $22.3(5.6)$ & $27.8(8.3)$ \\
\hline $\begin{array}{l}\text { Mean (SD) change from before to } \\
\text { after Ml¥ }\end{array}$ & $-1.6(4.5)$ & $1.7(4.5)$ & $6.5(6.7)$ & $-1.3(4.6)$ & $2.1(5.6)$ & $9.2(9.0)$ \\
\hline $\begin{array}{l}\text { Mean }(S D) \text { age at diagnosis } \\
\text { (years)§ }\end{array}$ & $64.5(8.8)$ & $64.9(8.5)$ & $65.1(8.2)$ & $65.8(9.5)$ & $66.1(8.9)$ & $66.1(8.9)$ \\
\hline $\begin{array}{l}\text { Mean (SD) body mass index } \\
\left(\mathrm{kg} / \mathrm{m}^{2}\right)\end{array}$ & $26.3(5.4)$ & $27.6(6.2)$ & $26.3(5.2)$ & $26.4(3.7)$ & $26.1(3.6)$ & $25.6(3.7)$ \\
\hline $\begin{array}{l}\text { Mean (SD) physical activity (MET } \\
\text { h/wk) }\end{array}$ & $9.4(13.5)$ & $13.4(18.4)$ & $20.1(20.8)$ & $25.9(33.6)$ & $37.0(54.0)$ & $40.4(35.0)$ \\
\hline \multicolumn{7}{|l|}{ Smoking status: } \\
\hline Never smoker & 25 & 30 & 38 & 28 & 36 & 41 \\
\hline Former smoker & 51 & 61 & 58 & 54 & 52 & 47 \\
\hline Current smoker & 24 & 9 & 4 & 9 & 4 & 1 \\
\hline Married & 64 & 69 & 69 & 85 & 90 & 88 \\
\hline Diabetes & 19 & 27 & 24 & 13 & 13 & 15 \\
\hline High blood pressure & 67 & 74 & 70 & 59 & 58 & 50 \\
\hline Increased cholesterol level & 71 & 80 & 79 & 68 & 63 & 64 \\
\hline Aspirin use & 61 & 62 & 64 & 78 & 82 & 81 \\
\hline Lipid lowering drug use & 42 & 50 & 55 & 48 & 57 & 50 \\
\hline CABGS & 53 & 53 & 63 & 70 & 76 & 74 \\
\hline \multicolumn{7}{|l|}{ Reproductive factors: } \\
\hline Premenopause & 5 & 4 & 4 & Not applicable & Not applicable & Not applicable \\
\hline Past PMH user & 29 & 29 & 28 & Not applicable & Not applicable & Not applicable \\
\hline Current PMH user & 57 & 57 & 64 & Not applicable & Not applicable & Not applicable \\
\hline \multicolumn{7}{|l|}{ Dietary intake: } \\
\hline Mean (SD) total energy (kcal/d) & $1619(538)$ & $1637(526)$ & $1592(518)$ & $1878(620)$ & $1946(646)$ & $1925(621)$ \\
\hline $\begin{array}{l}\text { Mean (SD) saturated fat (\% of } \\
\text { energy) }\end{array}$ & $11.1(3.2)$ & $9.2(2.3)$ & $7.0(2.1)$ & $10.8(3.0)$ & $8.8(2.4)$ & $6.1(2.0)$ \\
\hline $\begin{array}{l}\text { Mean (SD) n-3 fatty acids (\% of } \\
\text { energy) }\end{array}$ & $0.7(0.3)$ & $0.7(0.3)$ & $0.8(0.4)$ & $0.7(0.5)$ & $0.7(0.3)$ & $0.9(0.6)$ \\
\hline $\begin{array}{l}\text { Mean (SD) trans fatty acid (\% of } \\
\text { energy) }\end{array}$ & $1.8(0.8)$ & $1.5(0.5)$ & $1.0(0.5)$ & $1.8(0.8)$ & $1.5(0.6)$ & $0.9(0.5)$ \\
\hline Mean (SD) alcohol (g/d) & $6.0(12.8)$ & $4.3(9.1)$ & $2.9(5.4)$ & $13.4(17.1)$ & $9.1(12.3)$ & $6.3(10.3)$ \\
\hline Mean $(\mathrm{SD})$ folate $(\mu \mathrm{g} / \mathrm{d})$ & $389(229)$ & $488(262)$ & $613(294)$ & $542(318)$ & $699(331)$ & $874(449)$ \\
\hline Mean $(S D)$ cereal fiber $(\mathrm{g} / \mathrm{d})$ & $4.0(1.7)$ & $5.9(2.2)$ & $8.4(4.0)$ & $5.3(2.1)$ & $7.8(2.8)$ & $11.2(4.8)$ \\
\hline Mean (SD) fruit fiber $(\mathrm{g} / \mathrm{d})$ & $1.3(0.6)$ & $4.0(0.4)$ & $8.7(2.6)$ & $1.8(0.7)$ & $5.1(0.5)$ & $11.4(3.5)$ \\
\hline Mean (SD) legume fiber (g/d) & $0.2(0.1)$ & $1.0(0.1)$ & $3.4(1.6)$ & $0.4(0.3)$ & $1.7(0.2)$ & $5.3(2.1)$ \\
\hline \multicolumn{7}{|l|}{ Clinical characteristics: } \\
\hline Heart failure & Not available & Not available & Not available & 8 & 9 & 8 \\
\hline $\begin{array}{l}\text { Received acute therapy during } \\
\text { hospital stay }\end{array}$ & Not available & Not available & Not available & 34 & 34 & 36 \\
\hline Anterior MI & Not available & Not available & Not available & 39 & 48 & 45 \\
\hline ST elevation MI & Not available & Not available & Not available & 42 & 40 & 43 \\
\hline $\begin{array}{l}\text { Normal left ventricular ejection } \\
\text { fraction }\end{array}$ & Not available & Not available & Not available & 84 & 80 & 80 \\
\hline
\end{tabular}




\section{Table 1 (continued)}

Characteristics
Women

Lowest fifth
Third fifth

Highest fifth

\section{Lowest fifth}

Men

Third fifth

Highest fifth

Nutrients were energy adjusted.

$\mathrm{MET}=$ metabolic equivalent task; $\mathrm{CABGS=coronary}$ artery bypass surgery; $\mathrm{PMH}=$ postmenopausal hormone use.

*Baseline diet factors are taken from participant's first post-MI food frequency questionnaire; Lifestyle factors are taken from corresponding questionnaire by date of first post-Ml food frequency questionnaire.

†Pre-MI diet is taken from participant's most recent food frequency questionnaire before initial MI onset.

‡Change of diet from pre-MI to post-MI is calculated as change=(post-MI diet-pre-MI diet).

§Age is not age standardized. 


\begin{tabular}{|c|c|c|c|c|c|c|c|}
\hline \multirow[b]{2}{*}{ Estimates } & \multirow{2}{*}{$\begin{array}{l}\text { Continuous (per } \\
10 \mathrm{~g} \text { increment) }\end{array}$} & \multicolumn{5}{|c|}{ Fifths of fiber intake after MI } & \multirow[b]{2}{*}{$P$ for trend } \\
\hline & & First (lowest) & Second & Third & Fourth & Fifth (highest) & \\
\hline \multicolumn{8}{|l|}{ All cause mortality } \\
\hline \multicolumn{8}{|l|}{ Women $(n=682)$ : } \\
\hline Median intake (g/day) & - & 12.95 & 16.54 & 19.12 & 22.33 & 27.40 & - \\
\hline Cases/person year & - & $173 / 4183$ & $150 / 4247$ & $123 / 4171$ & $134 / 4195$ & $102 / 4214$ & - \\
\hline $\begin{array}{l}\text { Basic model adjusted } \\
\text { hazard ratio }(95 \% \mathrm{Cl})^{*}\end{array}$ & 0.65 (0.56 to 0.76$)$ & 1.00 & 0.85 (0.68 to 1.07$)$ & $0.67(0.53$ to 0.85$)$ & 0.74 (0.58 to 0.93$)$ & 0.50 (0.39 to 0.64$)$ & $<0.0001$ \\
\hline $\begin{array}{l}\text { Multivariate adjusted } \\
\text { hazard ratio }(95 \% \mathrm{Cl}) \dagger\end{array}$ & $0.82(0.68$ to 1.00$)$ & 1.00 & $0.94(0.74$ to 1.20$)$ & $0.80(0.61$ to 1.04$)$ & $0.98(0.74$ to 1.30$)$ & $0.71(0.51$ to 0.98$)$ & 0.07 \\
\hline \multicolumn{8}{|l|}{ Men $(n=451)$ : } \\
\hline Median intake & - & 16.34 & 20.90 & 24.36 & 28.50 & 35.60 & - \\
\hline Cases/person year & - & $104 / 3206$ & $92 / 3216$ & $93 / 3229$ & $83 / 3206$ & $79 / 3212$ & - \\
\hline $\begin{array}{l}\text { Basic model adjusted } \\
\text { hazard ratio }(95 \% \mathrm{Cl})^{*}\end{array}$ & 0.79 (0.68 to 0.91$)$ & 1.00 & 0.85 (0.64 to 1.13$)$ & 0.80 (0.60 to 1.07$)$ & $0.64(0.48$ to 0.87$)$ & $0.63(0.47$ to 0.86$)$ & 0.0008 \\
\hline $\begin{array}{c}\text { Multivariate adjusted } \\
\text { hazard ratio }(95 \% \mathrm{Cl}) \dagger\end{array}$ & 0.88 (0.72 to 1.07$)$ & 1.00 & 1.03 (0.75 to 1.42$)$ & 0.99 (0.71 to 1.38$)$ & 0.85 (0.59 to 1.23$)$ & $0.82(0.54$ to 1.25$)$ & 0.25 \\
\hline $\begin{array}{l}\text { Pooled multivariate } \\
\text { adjusted hazard ratio (95\% } \\
\mathrm{Cl})\end{array}$ & $\begin{array}{c}0.85(0.74 \text { to } \\
0.97) \ddagger\end{array}$ & 1.00 & 0.97 (0.80 to 1.18$)$ & 0.87 (0.71 to 1.07$)$ & $0.93(0.74$ to 1.16$)$ & $0.75(0.58$ to 0.97$) \S$ & 0.03 \\
\hline \multicolumn{8}{|l|}{ Cardiovascular mortality } \\
\hline \multicolumn{8}{|l|}{ Women $(n=336)$ : } \\
\hline Median intake & - & 12.95 & 16.54 & 19.12 & 22.33 & 27.40 & - \\
\hline Cases/person year & - & $80 / 4183$ & $76 / 4247$ & $56 / 4171$ & $76 / 4195$ & $48 / 4214$ & - \\
\hline $\begin{array}{l}\text { Basic model adjusted } \\
\text { hazard ratio }(95 \% \mathrm{Cl})^{*}\end{array}$ & 0.71 (0.58 to 0.88$)$ & 1.00 & $0.93(0.67$ to 1.28$)$ & 0.65 (0.46 to 0.93$)$ & $0.93(0.67$ to 1.28$)$ & $0.55(0.38$ to 0.79$)$ & 0.003 \\
\hline $\begin{array}{c}\text { Multivariate adjusted } \\
\text { hazard ratio }(95 \% \mathrm{Cl}) \dagger\end{array}$ & 0.95 (0.71 to 1.25$)$ & 1.00 & 1.00 (0.70 to 1.42$)$ & $0.74(0.50$ to 1.10$)$ & 1.27 (0.86 to 1.88$)$ & 0.85 (0.54 to 1.35$)$ & 0.83 \\
\hline \multicolumn{8}{|l|}{ Men $(n=222)$ : } \\
\hline Median intake & - & 16.34 & 20.90 & 24.36 & 28.50 & 35.60 & - \\
\hline Cases/person year & - & $46 / 3206$ & $47 / 3216$ & $47 / 3229$ & $41 / 3206$ & $41 / 3212$ & - \\
\hline $\begin{array}{l}\text { Basic model adjusted } \\
\text { hazard ratio }(95 \% \mathrm{Cl})^{*}\end{array}$ & $0.82(0.67$ to 1.00$)$ & 1.00 & $0.96(0.63$ to 1.46$)$ & 0.89 (0.58 to 1.35$)$ & $0.71(0.46$ to 1.10$)$ & 0.73 (0.47 to 1.12$)$ & 0.07 \\
\hline $\begin{array}{c}\text { Multivariate adjusted } \\
\text { hazard ratio }(95 \% \mathrm{Cl}) \dagger\end{array}$ & 0.87 (0.66 to 1.16$)$ & 1.00 & 1.09 (0.68 to 1.73$)$ & 0.93 (0.57 to 1.52$)$ & 0.85 (0.49 to 1.45$)$ & $0.89(0.49$ to 1.61$)$ & 0.52 \\
\hline $\begin{array}{l}\text { Pooled multivariate } \\
\text { adjusted hazard ratio (95\% } \\
\text { Cl) }\end{array}$ & $\begin{array}{c}0.91(0.75 \text { to } \\
1.11) \rrbracket\end{array}$ & 1.00 & $1.03(0.78$ to 1.37$)$ & $0.81(0.60$ to 1.10$)$ & 1.11 (0.81 to 1.52$)$ & $0.87(0.60 \text { to } 1.24)^{\star \star}$ & 0.46 \\
\hline
\end{tabular}

*Adjusted for time since MI onset, age at diagnosis (continuous), and calendar year.

†Additionally adjusted for total caloric intake (fifths of kcal), physical activity (fifths of metabolic equivalents/week), aspirin use (yes or no), diabetes (yes or no), high blood pressure (yes or no), use of lipid lowering drugs (yes or no), alcohol consumption ( $0 \mathrm{~g} /$ day; 0.1-9.9 g/day; 10-29.9 g/day; or $\geq 30 \mathrm{~g} / \mathrm{day}$ ), saturated fat intake (fifths of \% of total energy), n3 fatty acid intake (fifths of \% of total energy), trans fatty acid intake (fifths of \% of total energy), married (yes or no), body mass index $\left(<21 ; 21-22.9 ; 23-24.9 ; 25-27.4 ; 27.5-29.9 ;>30 \mathrm{~kg} / \mathrm{m}^{2}\right)$, coronary artery bypass surgery (yes or no), folate intake (fifths of $\mu \mathrm{g} / \mathrm{day}$ ), and pre-Ml intake (fifths). For women, additionally adjusted for smoking (never or missing; former; current, 1-14 cigarettes/day; current, 15-24 cigarettes/day; or current, $\geq 25$ cigarettes/day), status for postmenopausal hormone use (premenopause; never user; current user; former user).

For men, additionally adjusted for smoking (never or missing; former; current, <15 cigarettes/day; or current, $\geq 15$ cigarettes/day), heart failure (yes or no), left ventricular ejection fraction ( $\geq 40 \%,<40 \%$, or missing), and acute therapy during admission to hospital (angioplasty or thrombolytics, or none).

$\ddagger \mathrm{P}=0.62$ for heterogeneity.

$\S \mathrm{P}=0.59$ for heterogeneity.

$\mathbb{\Psi P}=0.66$ for heterogeneity.

${ }^{* *} \mathrm{P}=0.90$ for heterogeneity. 
Table 3| Multivariate adjusted hazard ratios for all cause and cardiovascular mortality according to changes of fiber intake from period before to after myocardial infarction (MI)

\begin{tabular}{|c|c|c|c|c|c|c|c|}
\hline \multirow[b]{2}{*}{ Estimates } & \multirow{2}{*}{$\begin{array}{l}\text { Continuous (per } \\
10 \mathrm{~g} \text { increment) }\end{array}$} & \multicolumn{5}{|c|}{ Fifths of changes of fiber intake from period before to after MI } & \multirow[b]{2}{*}{ P for trend } \\
\hline & & First (lowest) & Second & Third & Fourth & Fifth (highest) & \\
\hline \multicolumn{8}{|l|}{ All cause mortality } \\
\hline \multicolumn{8}{|l|}{ Women $(n=682)$ : } \\
\hline Median change & & -3.85 & 0.20 & 2.76 & 5.48 & 9.87 & \\
\hline Cases/person year & & $189 / 4206$ & $126 / 4209$ & $120 / 4202$ & $123 / 4196$ & $124 / 4196$ & \\
\hline $\begin{array}{l}\text { Basic model adjusted } \\
\text { hazard ratio }(95 \% \mathrm{Cl})^{*}\end{array}$ & $0.69(0.59$ to 0.80$)$ & 1.00 & $0.66(0.52$ to 0.84$)$ & 0.61 (0.48 to 0.77$)$ & 0.61 (0.48 to 0.77$)$ & $0.58(0.46$ to 0.74$)$ & $<0.0001$ \\
\hline $\begin{array}{l}\text { Multivariate adjusted } \\
\text { hazard ratio }(95 \% \mathrm{Cl}) \dagger\end{array}$ & 0.73 (0.60 to 0.88$)$ & 1.00 & 0.69 (0.53 to 0.89$)$ & $0.72(0.55$ to 0.93$)$ & 0.65 (0.49 to 0.86$)$ & $0.64(0.48$ to 0.86$)$ & 0.005 \\
\hline \multicolumn{8}{|l|}{ Men $(n=451)$ : } \\
\hline Median change & & -4.90 & 0.02 & 3.05 & 6.30 & 11.63 & \\
\hline Cases/person year & & $104 / 3206$ & $92 / 3216$ & $93 / 3229$ & $83 / 3206$ & $79 / 3212$ & \\
\hline $\begin{array}{l}\text { Basic model adjusted } \\
\text { hazard ratio }(95 \% \mathrm{Cl})^{\star}\end{array}$ & $0.84(0.72$ to 0.98$)$ & 1.00 & $1.01(0.76$ to 1.35$)$ & $0.95(0.71$ to 1.27$)$ & $0.83(0.62$ to 1.12$)$ & $0.77(0.57$ to 1.04$)$ & 0.04 \\
\hline $\begin{array}{c}\text { Multivariate adjusted } \\
\text { hazard ratio }(95 \% \mathrm{Cl}) \dagger\end{array}$ & 0.82 (0.68 to 1.00$)$ & 1.00 & 0.97 (0.71 to 1.33$)$ & 0.88 (0.63 to 1.23$)$ & $0.86(0.61$ to 1.20$)$ & $0.76(0.53$ to 1.10$)$ & 0.11 \\
\hline $\begin{array}{l}\text { Pooled multivariate } \\
\text { adjusted hazard ratio } \\
(95 \% \mathrm{Cl})\end{array}$ & $\begin{array}{c}0.77(0.68 \text { to } \\
0.90) \ddagger\end{array}$ & 1.00 & 0.80 (0.65 to 0.97$)$ & 0.78 (0.63 to 0.96$)$ & $0.73(0.58$ to 0.90$)$ & 0.69 (0.55 to 0.87$) \S$ & 0.002 \\
\hline \multicolumn{8}{|l|}{ Cardiovascular mortality } \\
\hline \multicolumn{8}{|l|}{ Women $(n=336)$ : } \\
\hline Median change & & -3.85 & 0.20 & 2.76 & 5.48 & 9.87 & \\
\hline Cases/person year & & $88 / 4206$ & $58 / 4209$ & $59 / 4202$ & $70 / 4196$ & $61 / 4196$ & \\
\hline $\begin{array}{l}\text { Basic model adjusted } \\
\text { hazard ratio }(95 \% \mathrm{Cl})^{*}\end{array}$ & $0.72(0.58$ to 0.90$)$ & 1.00 & $0.59(0.42$ to 0.83$)$ & 0.59 (0.42 to 0.83$)$ & $0.63(0.46$ to 0.88$)$ & $0.54(0.38$ to 0.76$)$ & 0.001 \\
\hline $\begin{array}{c}\text { Multivariate adjusted } \\
\text { hazard ratio }(95 \% \mathrm{Cl}) \dagger\end{array}$ & 0.83 (0.63 to 1.09$)$ & 1.00 & 0.62 (0.42 to 0.91$)$ & 0.69 (0.47 to 1.02$)$ & 0.68 (0.46 to 1.01$)$ & $0.65(0.42$ to 0.99$)$ & 0.09 \\
\hline \multicolumn{8}{|l|}{ Men $(n=222)$ : } \\
\hline Median change & & -4.90 & 0.02 & 3.05 & 6.30 & 11.63 & \\
\hline Cases/person year & & $46 / 3206$ & $47 / 3216$ & $47 / 3229$ & $41 / 3206$ & $41 / 3212$ & \\
\hline $\begin{array}{l}\text { Basic model adjusted } \\
\text { hazard ratio }(95 \% \mathrm{Cl})^{*}\end{array}$ & 0.79 (0.64 to 0.97$)$ & 1.00 & 0.98 (0.66 to 1.47$)$ & $0.80(0.53$ to 1.20$)$ & $0.68(0.45$ to 1.05$)$ & 0.75 (0.49 to 1.12$)$ & 0.06 \\
\hline $\begin{array}{l}\text { Multivariate adjusted } \\
\text { hazard ratio }(95 \% \mathrm{Cl}) \dagger\end{array}$ & 0.72 (0.54 to 0.94$)$ & 1.00 & $0.91(0.58$ to 1.41$)$ & $0.66(0.41$ to 1.05$)$ & 0.59 (0.36 to 0.97$)$ & $0.65(0.39$ to 1.08$)$ & 0.04 \\
\hline $\begin{array}{l}\text { Pooled multivariate } \\
\text { adjusted hazard ratio } \\
(95 \% \mathrm{Cl})\end{array}$ & $\begin{array}{c}0.72(0.61 \text { to } \\
0.84) \text { व }\end{array}$ & 1.00 & $0.74(0.55$ to 0.98$)$ & $0.69(0.51$ to 0.93$)$ & $0.64(0.47$ to 0.87$)$ & $0.65(0.47 \text { to } 0.90)^{\star *}$ & 0.01 \\
\hline
\end{tabular}

*Adjusted for time since MI onset, age at diagnosis (continuous), and calendar year.

†Additionally adjusted for aspirin use (never, new, always), diabetes (no, new, always), high blood pressure (no, new, always), use of lipid lowering drugs (never, new, always), married (never, always, not anymore), coronary artery bypass surgery (never, always, new), changes in smoking status (always never, always past, always current 1-14 cigarettes/day post-MI period, always current $\geq 15$ cigarettes/day post-MI period, quit smoking after MI 1-14 cigarettes/day pre-MI period, quit smoking after $\mathrm{MI} \geq 15$ cigarettes/day pre-MI period), and pre-Ml fiber intake (fifths).

For women, additionally adjusted for changes in total caloric intake (fifths of kcal), changes in physical activity (fifths of changes in metabolic equivalents/week), changes in alcohol consumption (fifths of changes in $\mathrm{g} /$ day), changes in body mass index (fifths of changes in $\mathrm{kg} / \mathrm{m}^{2}$ ), changes in saturated fat intake(fifths of changes in $\%$ of total energy), changes in $\mathrm{n} 3$ fatty acid intake (fifths of changes in $\%$ of total energy), changes in trans fatty acid intake (fifths of changes in \% of total energy), changes in folate intake (fifths of changes in $\mu \mathrm{g} /$ day), and status of postmenopausal hormone use (premenopause, never, current, former). For men, additionally adjusted for: changes in total caloric intake (thirds of kcal), changes in physical activity (thirds of changes in metabolic equivalents/week), changes in alcohol consumption (thirds of changes in $\mathrm{g} / \mathrm{day}$ ), changes in body mass index (thirds of changes in $\mathrm{kg} / \mathrm{m}^{2}$ ), changes in saturated fat intake (thirds of changes in $\%$ of total energy), changes in $\mathrm{n} 3$ fatty acid intake (thirds of changes in $\%$ of total energy), changes in trans fatty acid intake (thirds of changes in $\%$ of total energy), changes in folate intake (thirds of changes in $\mu \mathrm{g} /$ day), heart failure (yes or no), left ventricular ejection fraction ( $\geq 40 \%,<40 \%$, or missing), and acute therapy during admission to hospital (received angioplasty or thrombolytics, or none).

$\ddagger \mathrm{P}=0.35$ for heterogeneity.

$\S \mathrm{P}=0.47$ for heterogeneity. 
Table 3 (continued)

\begin{tabular}{|c|c|c|c|c|c|c|c|}
\hline \multirow[b]{2}{*}{ Estimates } & \multirow{2}{*}{$\begin{array}{l}\text { Continuous (per } \\
10 \mathrm{~g} \text { increment) }\end{array}$} & \multicolumn{5}{|c|}{ Fifths of changes of fiber intake from period before to after MI } & \multirow[b]{2}{*}{$P$ for trend } \\
\hline & & First (lowest) & Second & Third & Fourth & Fifth (highest) & \\
\hline \multicolumn{8}{|c|}{$\llbracket \mathrm{P}=0.53$ for heterogeneity. } \\
\hline${ }^{\star \star} \mathrm{P}=1.00$ for & & & & & & & \\
\hline
\end{tabular}




\section{Figure}

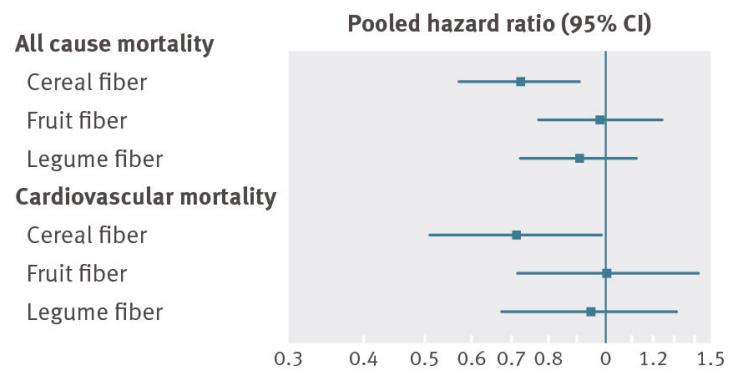

Pooled hazard ratios for all cause and cardiovascular mortality according to intake of fiber from cereal, fruits, and legumes in post-MI period (highest fifth versus lowest fifth). See footnote to table 2 for all adjustment variables 